Corrigendum

\title{
Corrigendum to "Optically stimulated luminescence dating of late Holocene raised strandplain sequences adjacent to Lakes Michigan and Superior, Upper Peninsula, Michigan, USA" [Quaternary Research 63 (2005) 122-135]
}

\author{
Erin P. Argyilan ${ }^{\mathrm{a}, *}$, Steven L. Forman ${ }^{\mathrm{b}}$, John W. Johnston ${ }^{\mathrm{c}}$, Douglas A. Wilcox ${ }^{\mathrm{d}}$ \\ ${ }^{a}$ Department of Geosciences, Indiana University Northwest, 3400 Broadway, Marram 243, Gary, IN 46408, USA \\ ${ }^{\mathrm{b}}$ Department of Earth and Environmental Sciences, University of Illinois at Chicago, $845 \mathrm{~W}$. Taylor St., M/C 186, Chicago, IL 60607, USA \\ ${ }^{\mathrm{c}}$ Department of Earth Sciences, University of Waterloo, CEIT Building, 200 University Ave. W., Waterloo, Ontario, Canada N2L $3 G 1$ \\ ${ }^{\mathrm{d} D e p a r t m e n t}$ of the Interior, U.S. Geological Survey, Great Lakes Science Center, 1451 Green Road, Ann Arbor, MI 48105, USA
}

Received 12 July 2005

Available online 18 August 2005

On page 126, please disregard lines 11-14 of column 1. A corrected Table 1 was included prior to publication and the ${ }^{14} \mathrm{C}$ ages were corrected for the $\sim 50$-yr offset relative to OSL ages. Therefore, the OSL and ${ }^{14} \mathrm{C}$ ages can be directly compared.

DOI of original article: $10.1016 /$ j.yqres.2004.12.001

* Corresponding author. Fax: +1 2199806673.

E-mail address: eargyila@iun.edu (E.P. Argyilan). 